\title{
JOB SATISFACTION \& JOB ENVIRONMENT : PENGARUHNYA TERHADAP INTENTION TURNOVER DI SEMARANG MEDICAL CENTER TELOGOREJO
}

\author{
Gerardus Cahyu Adhi Wicaksono \\ Paulus Wardoyo ${ }^{1)}$ \\ e-mail : paulus_w@usm.ac.id
}

\begin{abstract}
Abstrak
Tujuan studi ini adalah menganalisis pengaruh job satisfaction, job environment terhadap turnover intention dengan menggunakan internal motivation sebagai variable intervening. Studi ini dilatarbelakangi adanya perbedaan hasil penelitian atas pengaruh job satisfaction terhadap turnover intention. Unit penelitian adalah para perawat di SMC Telogorejo dengan menggunakan responden sebanyak 120 orang yang dipilih dengan memakai teknik purposive sampling.

Hasil studi menujukkan bahwa job satisfaction dan job environment berpengaruh terhadap turnover intention, namun demikian studi ini gagal membuktikan peran internal motivation sebagai variable intervening

Kata kunci : job satisfaction, job environment, internal motivation
\end{abstract}

\section{JOB SATISFACTION \& JOB ENVIRONMENT: EFFECT ON INTENTION TURNOVER IN SEMARANG MEDICAL CENTER TELOGOREJO Gerardus Cahyu Adhi Wicaksono Paulus Wardoyo ${ }^{1)}$ \\ e-mail : paulus_w@usm.ac.id}

\begin{abstract}
The purpose of the study is to analyze the influence of job satisfaction, job environment to turnover intention by using internal motivation as intervening variable. This study is based on differences in research on the influence of job satisfaction on turnover intention. The research unit is the nurses SMC Telogorejo, using the respondents as many as 120 people selected by using purposive sampling technique. The results showed that job satisfaction and job environment had an effect on turnover intention, however, this study failed to prove the role of internal motivation as intervening variable Key word : job satisfaction, job environment, internal motivation
\end{abstract}




\section{PENDAHULUAN}

Lingkungan yang berubah dengan cepat mengharuskan organisasi untuk merespons perubahan ini dengan cepat agar tetap berada dalam persaingan global. Organisasi sering harus mengubah struktur dan bentuk organisasi agar merespons perubahan organisasi. Perubahan organisasi radikal akan berdampak pada setiap individu yang berada dalam organisasi (Auliaand Welly, 2014). Proses seleksi dan perekrutan sama pentingnya baik untuk perusahan kecil dan besar. Berkenaan dengan sumber daya manusia, rekrutmen adalah prosedur untuk menemukan, dan melakukan induksi yang diinginkan kandidat ke perusahaan. Para ahli perekrutan ini terlibat dalam banyak langkah seperti calon sumber, melacak dan mengkaji pencalonan, daftar singkat pemohon, pengorganisasian dan pelaksanaan wawancara untuk karyawan (Ashrafq, 2016).

Turnover karyawan adalah proses individu yang mengambil hasil material dari organisasi yang mengakhiri keanggotaan organisasi . Ada kelebihan dan kekurangan untuk pergantian karyawan. Di satu sisi, karyawan berkualitas rendah bisa diganti; kreativitas, fleksibilitas dan kemampuan beradaptasi dari organisasi dapat ditingkatkan. Di sisi lain, biaya meninggalkan akan meningkat, biaya termasuk biaya eksplisit (Zhang, 2016). Turnover intention sering menjadi perhatian utama dalam penyusunan strategi organisasi. Turnover sukarela terutama akan merugikan organisasi dalam bentuk biaya penggantian pegawai untuk iklan untuk pencarian pegawai baru. Turnover intention juga berdampak negatif terhadap karyawan. Individu dapat menjadi korban fenomena 'rumput tetangga terlihat lebih hijau'.(Saraih et,al , 2017). Di sisi lain turnover intention adalah masalah serius terutama saat ini dimana karyawan meninggalkan organisasi atau organisasi memecatnya. Turnover intention adalah karyawan yang berencana untuk meninggalkan pekerjaan mereka. Turnover intention bisa bersifat sukarela atau tidak sukarela. Dalam turnover intention sukarela, karyawan meninggalkan organisasi dengan sukarela. Hal itu terjadi ketika karyawan memiliki peluang pilihan yang terbaik. Sementara turnover intention tidak sukarela terjadi ketika organisasi tidak puas dengan kinerja karyawan dan membuat keputusan untuk memecatnya (Rizwan, 2014).

Berpijak dari hasil penelitian terdahulu, ditemukan adanya hasil penelitian yang berbeda seperti yang dilakukan oleh Saeed (2014) yang menemukan bahwa job satisfaction memiliki pengaruh yang negative terhadap job intentition, sebaliknya Ashrafq (2016) dalam studinya menyimpulkan job satisfaction berpengaruh terhadap turnover intention. Studi yang dilakukan oleh Lee (2011) menyatakan job satisfaction tidak berpengaruh secara langsung terhadap turnover intention, sebaliknya Rafiqul (2016) menyatakan job satisfaction berpengaruh positif terhadap turnover intention. Astri (2014) menyatakan job satisfaction berdampak negatif terhadap turnover intention. Noorliza (2016) menyatakan job satisfaction berpengaruh terhadap turnover intention. Internal motivation adalah perilaku karyawan dengan sukarela melakukan pekerjaan secara lebih produktif dan saling bekerja sama dengan tim yang berasal dari kemauan diri sendiri. Internal motivation jika dihubungkan dengan hierarki kebutuhan manusia maka akan menyangkut kebutuhan yang tingkatnya lebih tinggi (Gofur et,al 2017). Internal motivation berasal dari dalam individu, ia bekerja sebagai kekuatan yang berasal dari kepuasan dan pemenuhan batin atau dari kewajiban yang dialokasikan karena jelas berdampak langsung, eksekusi dan bekerja sebagai atribut untuk meningkatkan kepribadian seseorang (Bakhtawar, 2016). Oleh karena itu penelitian ini menambahkan internal motivation sebagai variabel intervening, yang diharap dapat menjawab pengaruh langsung maupun tidak secara langsung antara variabel job environment dan job satisfaction terhadap turnover intention. 
Berpijak pada permasalahan yang ada, maka rumusan permasalahan penelitian ini adalah bagaimana membangun sebuah model penelitian yang dapat digunakan untuk menurunkan turnover intention

\section{TELAAH PUSTAKA}

\section{Turnover Intention}

Turnover intention adalah proses individu yang mengambil hasil material dari organisasi yang mengakhiri keanggotaan organisasi (Zhang, 2016). Tingginya tingkat turnover intention akan menjadi masalah serius untuk perusahaan karena nantinya perusahaan harus kembali melakukan rekruitmen jika karyawan yang ada memutuskan untuk keluar (Dwi, 2014). Turnover menggambarkan pemikiran individu untuk keluar, mencari pekerjaan di perusahaan lain, serta keinginan meninggalkan organisasi. Turnover intention mencerminkan keinginan seseorang untuk meninggalkan perusahaan dan mencari alternatif pekerjaan lain (Andini, 2006). Tujuan karyawan untuk meninggalkan organisasi dapat menjadi komponen penting dari kinerja organisasi dan tidak ada organisasi yang memiliki kemewahan untuk mengabaikan fenomena ini (Kamasak, 2011).

Turnover intention juga disebut sebagai turnover plan atau turnover tendency. Turnover Intention adalah kecenderungan perilaku karyawan untuk mencoba meninggalkan organisasi ditempat mereka bekerja, yang dapat menyebabkan karyawan keluar dari organisasi. Banyak penelitian menunjuk pada turnover intention sebagai anteseden utama tindakan turnover seseorang (Chen, 2014).Turnover intention dapat digambarkan seberapa lama karyawan akan menetap pada suatu organisasi. Untuk mengurangi turnover intention, organisasi dapat menawarkan paket kompensasi strategis terutama dengan menekankan kinerja dan tanggung jawab (Cinar, 2014). Turnover intention mengacu pada niat seorang karyawan untuk mencari perubahan pada situasi profesional mereka saat ini (Cho et,al, 2009).

Turnover intention dapat dipahami sebagai karyawan yang meninggalkan organisasi atau profesi secara sukarela. Telah diamati bahwa perputaran sukarela adalah konstruksi interdisipliner dan multidimensional. Masalah turnover sukarela membentang di luar keseluruhan karyawan dan organisasi. Akademisi tertarik pada turnover intention sebagai pendahulu perilaku turnover selama enam dekade terakhir (Jha, 2009).

Definisi konseptual untuk maksud turnover adalah kekuatan relatif dari niat individu untuk meninggalkan organisasi (Kumar, 2008). Turnover intention adalah keinginan untuk berpindah, belum sampai pada tahap realisasi yaitu melakukan perpindahan dari satu tempat kerja ke tempat kerja lainnya (Firmanto, 2013).

\section{Internal Motivation}

Motivasi dapat diartikan sebagai kekuatan (energi) seseorang yang dapat menimbulkan tingkat persistensi dan entusiasmenya dalam melaksanakan suatu kegiatan, baik yang bersumber dari dalam diri individu itu sendiri (internal motivation) maupun dari luar individu (motivasi ekstrinsik). Seberapa kuat motivasi yang dimiliki individu akan banyak menentukan terhadap kualitas perilaku yang ditampilkannya, baik dalam konteks belajar, bekerja maupun dalam kehidupan lainnya (Sudrajat 2008).

Ada daftar panjang berbagai jenis motivasi yang terjadi di tempat kerja seperti kecenderungan untuk melakukan pekerjaan yang berkualitas, melakukan kegiatan ekstrakurikuler, untuk tetap lembur, melakukan pekerjaan untuk orang lain, atau melakukan 
pekerjaan untuk diri sendiri (Prysmakova, 2017). Seperti yang baru saja disebutkan, internal motivation biasanya dibangun di atas aspek lain-seperti kegunaan sosial pekerjaan dan kontribusi bagi masyarakat. Namun, internal motivation mereka juga bisa memiliki fokus yang berkaitan dengan diri sendiri, misalnya, sebuah kesempatan untuk pemenuhan diri.

Internal motivation pada awalnya didefinisikan sebagai beberapa kepentingan inheren dalam sebuah tugas, yang tidak dapat diturunkan dari lingkungan ekonomi. Dengan demikian, perilaku intrinsik termotivasi bertujuan untuk menghasilkan konsekuensi imbalan internal tertentu yang terlepas dari penghargaan ekstrinsik manapun (Romaniuc, 2015). Internal motivation adalah perilaku karyawan dengan sukarela melakukan pekerjaan secara lebih produktif dan saling bekerja sama dengan tim yang berasal dari kemauan diri sendiri. Internal motivation jika dihubungkan dengan hierarki kebutuhan manusia maka akan menyangkut kebutuhan yang tingkatnya lebih tinggi (Gofur et,al 2017). Internal motivation berasal dari dalam individu, ia bekerja sebagai kekuatan yang berasal dari kepuasan dan pemenuhan batin atau dari kewajiban yang dialokasikan karena jelas berdampak langsung, eksekusi dan bekerja sebagai atribut untuk meningkatkan kepribadian seseorang (Bakhtawar, 2016).

\section{Job Satisfaction}

Job satisfaction dianggap sebagai hasil dari pengalaman karyawan dalam hubungannya dengan nilai sendiri seperti apa yang dikehendaki dan diharapkan dari pekerjaannya. Job satisfaction merupakan suatu sikap dari karyawan yang menggambarkan sikap positif atau negatif dari pencapaian dalam pekerjaannya (Agung, 2012). Job satisfaction adalah tingkat perasaan menyenangkan yang diperoleh dari penilaian pekerjaan seseorang atau pengalaman kerja (Anisa, 2017). Job satisfaction sangat penting karena hal ini menyumbang keberhasilan perusahaan, antara lain dapat meningkatkan produktivitas karyawan.

Job satisfaction adalah sekumpulan perasaan menyenangkan dan tidak menyenangkan terhadap pekerjaan mereka (Ayu et,al 2016). Job satisfaction dapat didefinisikan sebagai perasaan dan reaksi individu terhadap lingkungan pekerjaannya. Job satisfaction adalah perasaan seseorang terhadap pekerjaannya, ini berarti bahwa konsep job satisfaction dapat dilihat sebagai hasil interaksi karyawan terhadap job environment nya (Saryanto, 2016).

Inti dari job satisfaction adalah persepsi atau nuansa antara keinginan karyawan dengan hadiah aktual yang diterima oleh karyawan (Daniel, 2016). Job satisfaction ini adalah respon sikap karyawan terhadap organisasinya. Sebagai sikap, job satisfaction dikonseptualisasikan sebagai komponen evaluatif, kognitif dan afektif (Kumar, 2008). Job satisfaction yang dirasakan individu dapat mempengaruhi niat untuk keluar. Evaluasi terhadap berbagai alternatif pekerjaan, nantinya akan mewujudkan terjadinya turnover karena individu yang memilih keluar organisasi akan mengharapkan hasil yang lebih memuaskan di tempat lain. Job satisfaction merupakan orientasi individu yang berpengaruh terhadap peran dalam bekerja dan karakteristik dari pekerjaanya (Andini, 2006).

\section{Job environment}

Job environment adalah segala sesuatu yang berada disekitar karyawan yang mempengaruhi dirinya dalam menjalankan dan menyelesaikan tugas-tugas yang diberikan kepadanya dalam suatu wilayah (Khairani, 2013). Job environment adalah segala sesuatu yang ada disekitar para pekerja yang dapat mempengaruhi dirinya dalam menjalankan tugastugas yang dibebankan (Pima et,all 2014). 
Job environment merupakan segala sesuatu yang berada disekitar para pekerja baik secara fisik maupun non-fisik serta hubungannya dengan pekerja tersebut (Suryo, 2016). Job environment merupakan segala sesuatu yang ada di sekitar para pekerja dan yang dapat mempengaruhi dirinya dalam menjalankan tugas yang dia emban atau yang menjadi tanggung jawabnya (Mamiharisoa, 2015).

Job environment yang menarik dan mendukung dapat digambarkan sebagai lingkungan yang menarik individu ke dalam profesi yang sehat, mendorong mereka untuk tetap berada dalam kinerja yang sehat dan memungkinkan mereka tampil secara efektif. Tujuan untuk menyediakan job environment yang menarik adalah dengan menciptakan insentif untuk memasuki kinerja yang sehat (Oswald, 2012). Job environment mengacu pada suasana organisasi tempat karyawan melakukan pekerjaan mereka (Hanaysha, 2016).

\section{Hubungan Logis Antar Variabel Dan Perumusan Hipotesis}

\section{Hubungan job satisfaction terhadap internal motivation}

Semakin dekat korespondensi antara preferensi individu dan perilaku organisasi, semakin besar probabilitas kepuasan karyawan terhadap pekerjaan mereka (Prysmakova, 2017). Penelitian Baez (2017) menyatakan dampak yang positif signifikan antara job satisfaction dan motivasi. Penelitian Bakhtawar (2016) menyatakan hubungan yang tidak terlalu signifikan antara job satisfaction dan motivasi, sedangkan penelitian Agung et,al (2012) menyatakan job satisfaction tidak berpengaruh secara signifikan terhadap motivasi.

H1 : Job satisfaction berpengaruh terhadap internal motivation

\section{Hubungan job environment terhadap internal motivation}

Job environment merupakan salah satu faktor yang dapat mempengaruhi produktivitas kerja dan efektivitas kerja pegawai. Yang bentuknya dapat berupa lingkungan materiil seperti tempat dan sarana produksi. Hasil penelitian Moh. Mujib (2013), Lezita (2010), Rita Astarina et,al (2017) menyatakan bahwa job environment berpengaruh signifikan terhadap motivasi. $H 2$ : Job environment berpengaruh terhadap internal motivation

\section{Hubungan job satisfaction terhadap turnover intention}

Pekerja yang puas lebih loyal terhadap organisasinya. Hal ini mengurangi turnover karyawan dan lebih cepat menciptakan tingkat kepercayaan yang tinggi di antara mereka (Prysmakova, 2017). Penelitian Saad Ahmed et,al (2015), Rita Andini (2006), Anoki (2016), menyatakan hubungan yang negatif tidak signifikan antara job satisfaction dengan keinginan keluar karyawan.

H3 : Job satisfaction berpengaruh terhadap turnover intention

\section{Hubungan internal motivation terhadap turnover intention}

Perilaku intrinsik termotivasi bertujuan untuk menghasilkan konsekuensi imbalan internal tertentu yang terlepas dari penghargaan ekstrinsik manapun (Romaniuc, 2015). Peneliti Arin Dewi et,al (2016), Yuliandri Dwi et,al (2014), menyatakan ada pengaruh signifikan antara internal motivation terhadap keinginan karyawan untuk keluar. Sedangkan penelitian Firda Widiawati et,al (2017) menyatakan hubungan yang positif signifikan antara internal motivation dengan keinginan untuk keluar karyawan. 


\section{H4 : Internal motivation berpengaruh terhadap turnover intention}

\section{Hubungan job environment terhadap turnover intention}

Salah satu faktor turnover tinggi di tempat kerja adalah job environment organisasi yang terdiri dari komunikasi di tempat kerja, lingkungan politik, rekan kerja dan perilaku manajer tidak akan memuaskan karyawan. Penelitian Ridwan Suryo (2016), Mamiharisoa (2015), menyatakan job environment berpengaruh negatif terhadap keingingan keluar karyawan. Sedangkan penelitian Muhamman Imran (2012) menyatakan ada pengaruh yang signifikan antara job environment dan keinginan untuk keluar karyawan.

H5 : Job environment berpengaruh terhadap turnover intention

\section{Kerangka Pemikiran}

Model penelitian ini merupakan pengembangan dari peneliti terdahulu; Mujib (2013); Lezita (2010); Astarina et,al (2017); Andre (2017); Bakhtawar (2016); Agung et,al (2012); Suryo (2016); Mamiharisoa (2015); Imran (2012); Ahmed et,al (2015); Andini (2006); Anoki (2016); Dewi et,al (2016); Dwi et,al (2014); Widiawati et,al (2017).Selain itu adanya issue mengenai perbedaan hasil penelitian terdahulu mengenai job satifaction terhadap turnover intention, maka dalam penelitina ini perbedaan itu akan diselesaikan dengan memasukan variable internal motivation sebagai variabel intervening.

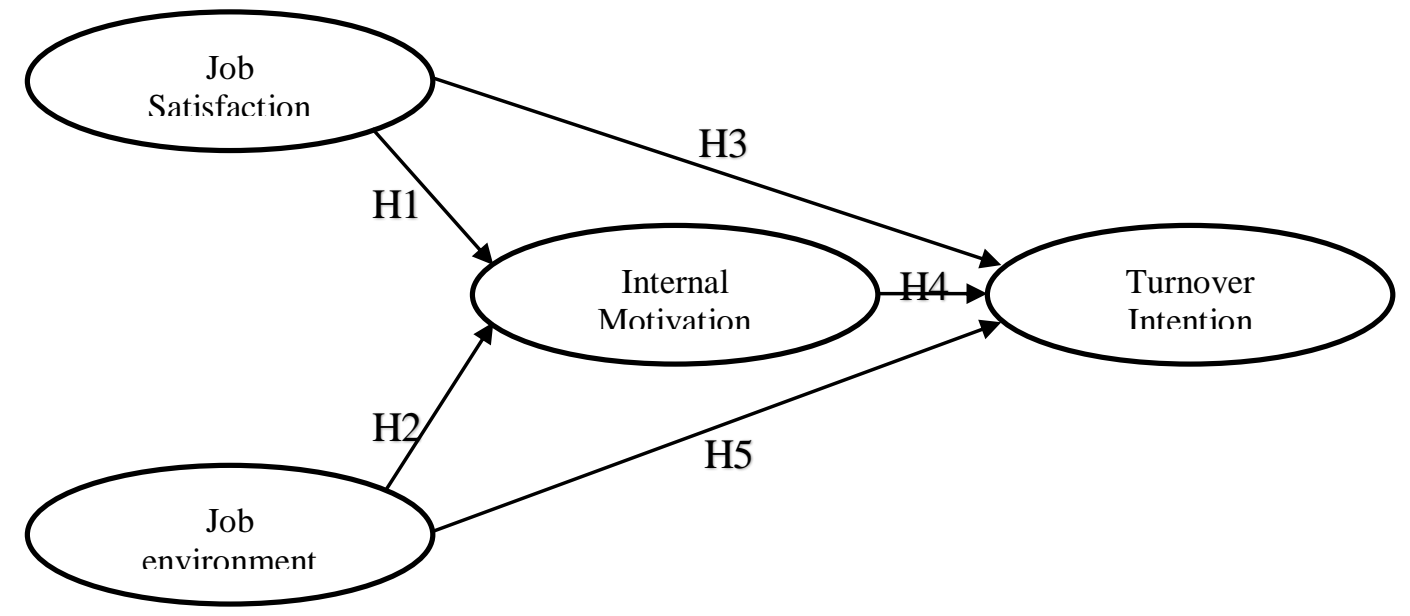

Gambar 2.1

Kerangka Pemikiran

\section{METODE PENELITIAN}

Jenis penelitian yang digunakan dalam penelitian ini adalah jenis explanatory yaitu menjelaskan pengaruh antar variabel tertentu melalui pengujian hipotesis. Data yang digunakan dalam penelitian ini adalah data primer, sedangkan unit analisis dalam penelitian ini adalah perawat Semarang Medical Center Telogorejo. Jumlah populasi seluruhnya adalah 365 orang, jumlah sampel yang digunakan dalam penelitian ini sebanyak 10 kali jumlah indikator, sehingga diperoleh sampel sebanyak 120 orang. Sampel dipilih dengan menggunakan cara purposive sampling, dengan kriteria pengalaman kerja kurang dari 12 bulan, memiliki latar belakang 
pendidikan perawat, berstatus single. Pengolahan data dalam penelitian ini dilakukan dengan bantuan software Lisrel 9.30 versi student. Analisis deskriptif dilakukan untuk mengetahui jawaban dari responden terhadap masing-masing variabel job satisfaction, job environment, internal motivation dan keinginan untuk keluar.

Untuk mengetahui frekuensi intensitas kondisi masing-masing variabel dapat diketahui dengan perkalian antara skor tertinggi dalam setiap variabel dengan jumlah pertanyaan yang ada setiap variabel yang kemudian dibagi menjadi 5 kategori, dengan menggunakan formula RS (rentang skala) $=(\mathrm{m}-\mathrm{n}) / \mathrm{k}$ dimana $\mathrm{m}=$ skor tertinggi dan $\mathrm{n}$ skor terendah, sedangkan $\mathrm{k}=$ banyaknya kelas.

Berdasarkan hasil perhitungan rentang skala diatas, maka kategori jawaban responden dapat dibagi seperti berikut :

$1,00-2,80$ : Sangat rendah atau sangat tidak baik yang menunjukan kondisi variabel pada posisi yang sangat rendah atau sangat tidak baik

2,81-4,60 : Rendah atau tidak baik yang menunjukan kondisi variabel pada posisi rendah atau tidak baik

4,61-6,40 : Sedang atau cukup yang menunjukan kondisi variabel pada posisi sedang atau cukup

6,41-8,20 : Tinggi atau baik yang menunjukan kondisi variabel pada posisi tinggi atu cukup

$8,21-10,00$ : Sangat tinggi atau sangat baik yang menunjukan kondisi variabel pada posisi sangat tinggi atau sangat baik

Sedangkan skala pengukuran dimulai dari 1-10. Definisi operasional variable dalam penelitian ini adalah sebagai berikut :

\section{Tabel 1 Definisi Operasional Variabel}

\begin{tabular}{|l|l|l|l|}
\hline No & \multicolumn{1}{|c|}{ Definisi Operasional Variabel } & \multicolumn{1}{|c|}{ Indikator } \\
\hline 1 & $\begin{array}{l}\text { Turnover intention karyawan adalah proses individu yang } \\
\text { mengambil hasil material dari organisasi yang mengakhiri } \\
\text { keanggotaan organisasi (Yanjuang, 2016). }\end{array}$ & $\begin{array}{l}\text { 1. Pencarian pekerjaan } \\
\text { 2. Pemikiran untuk keluar } \\
3 . \text { Memimpikan } \\
\text { diperusahaan } \\
\text { (Firmanto, 2013) }\end{array}$ \\
\hline 2 & $\begin{array}{l}\text { Internal motivation pada awalnya didefinisikan sebagai } \\
\text { beberapa kepentingan inheren dalam sebuah tugas, yang } \\
\text { tidak dapat diturunkan dari lingkungan ekonomi } \\
\text { (Romaniuc, 2015). }\end{array}$ & $\begin{array}{l}\text { 1. Memanfaatkan potensi } \\
\text { 2. Belajar hal baru } \\
\text { 3. Kreatif (Gofur et,al 2017) }\end{array}$ \\
\hline 3 & $\begin{array}{l}\text { Job satisfaction merupakan suatu sikap dari individu atau } \\
\text { karyawan yang menggambarkan sikap positifatau negatif } \\
\text { dari pencapaian atau achievement dalam pekerjaannya } \\
\text { (Agung, 2012). }\end{array}$ & $\begin{array}{l}\text { 1. Pekerjaan itu sendiri } \\
\text { 2. Kompensasi yang diterima } \\
\text { Kesempatan promosi }\end{array}$ \\
\hline 4 & $\begin{array}{l}\text { Job environment adalah segala sesuatu yang berada } \\
\text { disekitar karyawan yang mempengaruhi dirinya dalam } \\
\text { menjalankan dan menyelesaikan tugas-tugas yang } \\
\text { diberikan kepadanya dalam suatu wilayah (Khairani, } \\
\text { 2013) }\end{array}$ & $\begin{array}{l}\text { 1. Hubungan antar karyawan } \\
\text { 2. Suasana kerja } \\
\text { 3asilitas-fasilitas } \\
\text { karyawan kerja }\end{array}$ \\
\hline
\end{tabular}




\section{HASIL DAN PEMBAHASAN}

\section{Deskripsi Variabel Job Satisfaction}

Untuk mengetahui bagaimana tanggapan responden terhadap kuesioner variabel $J o b$ Satisfaction (X1) dapat dilihat pada tabel berikut ini :

Tabel 2 Tanggapan Responden Terhadap Job Satisfaction (X1)

\begin{tabular}{|c|c|c|c|c|c|c|c|c|c|c|c|c|c|}
\hline \multirow{2}{*}{ No. } & \multirow{2}{*}{ Indikator Job Satisfaction } & \multicolumn{10}{|c|}{ Frekuensi tanggapan Responden } & \multirow{2}{*}{$\begin{array}{l}\text { Total } \\
\text { Skor }\end{array}$} & \multirow{2}{*}{$\begin{array}{l}\text { Rata } \\
\text { Rata }\end{array}$} \\
\hline & & 1 & 2 & 3 & 4 & 5 & 6 & 7 & 8 & 9 & 10 & & \\
\hline 1 & Pekerjaan Itu Sendiri & 0 & 2 & 1 & 0 & 8 & 13 & 27 & 37 & 22 & 10 & 908 & 7.5 \\
\hline 2 & Kompensasi yg diterima & 0 & 2 & 0 & 1 & 7 & 8 & 26 & 49 & 19 & 8 & 916 & 7.6 \\
\hline 3 & Kesempatan Promosi & 4 & 0 & 6 & 1 & 2 & 6 & 23 & 57 & 15 & 6 & 884 & 7.3 \\
\hline \multicolumn{13}{|c|}{ Rata-rata keseluruhan } & 7.4 \\
\hline
\end{tabular}

Berdasarkan tabel di atas dapat diketahui bahwa jawaban responden terhadap variabel job satisfaction dengan rata-rata keseluruhan 7.4 dan masih dalam kategori tinggi atau baik, sehingga dapat dijustifikasi bahwa responden merasakan adanya kepuasan dengan pekerjaan yang ditekuninya,

\section{Deskripsi Variabel Job environment}

Untuk mengetahui bagaimana tanggapan responden terhadap kuesioner variabel Job environment $(\mathrm{X} 2)$ dapat dilihat pada tabel berikut ini :

Tabel 3 Tanggapan Responden Terhadap Job environment (X2)

\begin{tabular}{|c|c|c|c|c|c|c|c|c|c|c|c|c|c|}
\hline \multirow{2}{*}{ No. } & \multirow{2}{*}{ Indikator Job environment } & \multicolumn{10}{|c|}{ Frekuensi tanggapan Responden } & \multirow{2}{*}{$\begin{array}{l}\text { Total } \\
\text { Skor }\end{array}$} & \multirow{2}{*}{$\begin{array}{l}\text { Rata } \\
\text { Rata }\end{array}$} \\
\hline & & 1 & 2 & 3 & 4 & 5 & 6 & 7 & 8 & 9 & 10 & & \\
\hline 1 & Hubungan Antar Karyawan & 0 & 1 & 2 & 1 & 0 & 1 & 30 & 52 & 24 & 9 & 950 & 7.9 \\
\hline 2 & Suasana Kerja & 0 & 0 & 0 & 2 & 4 & 3 & 23 & 59 & 23 & 6 & 946 & 7.8 \\
\hline 3 & Fasilitas-fasilitas Karyawan & 1 & 1 & 1 & 2 & 2 & 7 & 29 & 42 & 28 & 7 & 921 & 7.7 \\
\hline \multicolumn{13}{|c|}{ Rata-rata keseluruhan } & 7.8 \\
\hline
\end{tabular}

Berdasarkan tabel diatas dapat diketahui bahwa jawaban responden terhadap variabel job environment dengan rata-rata keseluruhan 7.8 masuk dalam kategori tinggi. Dari hasil perhitungan tersebut dapat dilakukan justifikasi bahwa responden merasa puas dan nyaman dengan suasana di kerja

\section{Deskripsi Variabel Internal Motivation}

Untuk mengetahui bagaimana tanggapan responden terhadap kuesioner variabel Internal Motivation (Y1) dapat kita lihat pada tabel berikut ini : 
Tabel 4 Tanggapan Responden Terhadap Internal Motivation (Y1)

\begin{tabular}{|c|c|c|c|c|c|c|c|c|c|c|c|c|c|}
\hline \multirow{2}{*}{ No. } & \multirow{2}{*}{$\begin{array}{c}\text { Indikator Internal } \\
\text { Motivation }\end{array}$} & \multicolumn{10}{|c|}{ Frekuensi tanggapan Responden } & \multirow{2}{*}{$\begin{array}{l}\text { Total } \\
\text { Skor }\end{array}$} & \multirow{2}{*}{$\begin{array}{l}\text { Rata } \\
\text { Rata }\end{array}$} \\
\hline & & 1 & 2 & 3 & 4 & 5 & 6 & 7 & 8 & 9 & 10 & & \\
\hline 1 & Memanfaatkan Potensi & 1 & 0 & 6 & 3 & 7 & 10 & 43 & 29 & 15 & 6 & 854 & 7.1 \\
\hline 2 & Belajar Hal Baru & 2 & 0 & 1 & 6 & 6 & 12 & 39 & 32 & 14 & 8 & 866 & 7.2 \\
\hline 3 & Kreatif & 0 & 1 & 2 & 6 & 18 & 23 & 31 & 25 & 9 & 5 & 808 & 6.7 \\
\hline & & & & ke & & & & & & & & & 7 \\
\hline
\end{tabular}

Berdasarkan tabel diatas dapat diketahui bahwa jawaban responden terhadap variabel internal motivation dengan rata-rata keseluruhan 7 dan masuk dalam kategori tinggi, dengan demikian dapat dijustifikasi bahwa secara rata-rata internal motivation dari responden adalah cukup atau sedang

\section{Deskripsi Variabel Turnover Intention}

Untuk mengetahui bagaimana tanggapan responden terhadap kuesioner variabel Turnover Intention dapat dilihat pada tabel berikut ini :

Tabel 5 Tanggapan Responden Terhadap Turnover Intention

\begin{tabular}{|c|c|c|c|c|c|c|c|c|c|c|c|c|c|}
\hline \multirow{2}{*}{ No. } & \multirow{2}{*}{$\begin{array}{c}\text { Indikator Turnover } \\
\text { Intention }\end{array}$} & \multicolumn{10}{|c|}{ Frekuensi tanggapan Responden } & \multirow{2}{*}{$\begin{array}{l}\text { Total } \\
\text { Skor }\end{array}$} & \multirow{2}{*}{$\begin{array}{l}\text { Rata } \\
\text { Rata }\end{array}$} \\
\hline & & 1 & 2 & 3 & 4 & 5 & 6 & 7 & 8 & 9 & 10 & & \\
\hline 1 & Pencarian Pekerjaan & 0 & 0 & 1 & 2 & 4 & 11 & 48 & 29 & 18 & 7 & 897 & 7.4 \\
\hline 2 & Pemikiran Untuk Keluar & 0 & 0 & 0 & 4 & 9 & 17 & 49 & 24 & 11 & 6 & 857 & 7.1 \\
\hline 3 & Memimpikan Karir & 0 & 0 & 3 & 6 & 23 & 21 & 29 & 28 & 8 & 2 & 793 & 6.6 \\
\hline \multicolumn{13}{|c|}{ Rata-rata keseluruhan } & 7.03 \\
\hline
\end{tabular}

Berdasarkan tabel di atas dapat diketahui bahwa jawaban responden terhadap variabel keinginan untuk keluar dengan rata-rata keseluruhan 7.03 hal ini masuk dalam kategori tinggi

\section{Uji Normalitas}

Dengan data primer yang didapat melalui kuesioner, peneliti melanjutkan uji instrumen dengan pertama-tama melakukan uji normalitas. Data yang dinyatakan normal adalah data yang mempunyai nilai Skewness dan Kurtosis di atas 0.5. Uji normalitas dilakukan dengan bantuan software statistik Lisrel Student Version 9.30. Hasil uji normalitas dapat dilihat pada gambar berikut ini : 


\begin{tabular}{|c|c|c|c|c|c|c|}
\hline \multirow{3}{*}{$\begin{array}{l}\text { Test of } \\
\text { Variable }\end{array}$} & Univariat & \multicolumn{3}{|c|}{ Normality for Continuous } & \multicolumn{2}{|l|}{ Variables } \\
\hline & \multicolumn{2}{|c|}{ Skewness } & \multicolumn{2}{|c|}{ Kurtosis } & \multirow{2}{*}{$\begin{array}{l}\text { Skewness and } \\
\text { Chi-Square }\end{array}$} & \multirow{2}{*}{$\begin{array}{l}\text { Rurtosis } \\
\text { P-Value }\end{array}$} \\
\hline & z-Score & P-Value & z-Score & P-Value & & \\
\hline $\mathrm{X} 1 \mathrm{~A}$ & -0.387 & 0.699 & -0.136 & 0.892 & 0.168 & 0.919 \\
\hline $\mathrm{X} 1 \mathrm{~B}$ & -0.351 & 0.726 & -0.036 & 0.971 & 0.124 & 0.940 \\
\hline $\mathrm{x} 1 \mathrm{C}$ & 0.090 & 0.928 & -1.043 & 0.297 & 1.095 & 0.578 \\
\hline $\mathrm{X} 2 \mathrm{~A}$ & -0.528 & 0.598 & -0.200 & 0.841 & 0.318 & 0.853 \\
\hline $\mathrm{x} 2 \mathrm{~B}$ & -0.511 & 0.609 & -0.315 & 0.753 & 0.360 & 0.835 \\
\hline $\mathrm{x} 2 \mathrm{C}$ & -0.390 & 0.696 & -0.399 & 0.690 & 0.312 & 0.856 \\
\hline Y1A & -0.131 & 0.896 & -0.507 & 0.612 & 0.274 & 0.872 \\
\hline Y1B & 0.211 & 0.833 & -0.779 & 0.436 & 0.651 & 0.722 \\
\hline Y1C & -0.246 & 0.806 & 0.062 & 0.950 & 0.064 & 0.968 \\
\hline $\mathrm{Y} 2 \mathrm{~A}$ & -0.181 & 0.857 & -0.386 & 0.700 & 0.181 & 0.913 \\
\hline $\mathrm{Y} 2 \mathrm{~B}$ & -0.142 & 0.887 & -0.264 & 0.792 & 0.090 & 0.956 \\
\hline $\mathrm{Y} 2 \mathrm{C}$ & -0.216 & 0.829 & 0.034 & 0.973 & 0.048 & 0.976 \\
\hline
\end{tabular}

\section{Gambar 1 Uji normalitas}

Pada gambar 4.1 dapat diketahui bahwa nilai P-value semua indikator yang ada pada kolom Skewness dan Kurtosis berdistribusi normal ( $<0.5$ ).

\section{Uji jalur}

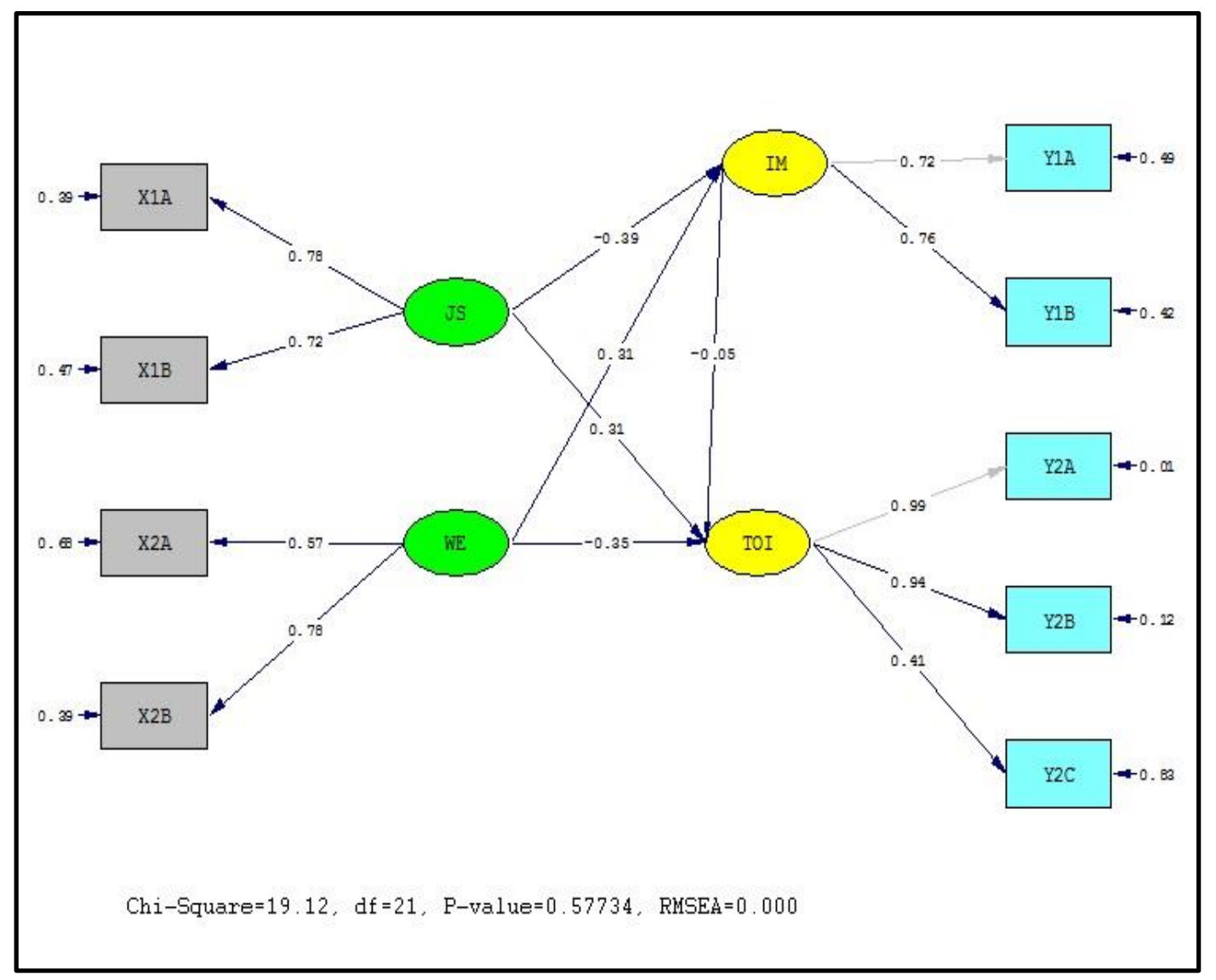

Gambar 2 Uji jalur revisi 
Berdasarkan uji jalur yang dilakukan dengan dropping beberapa indikator seperti x1c dan x2c maka didapatkan hasil seperti gambar 4.4 dengan variabel job satisfaction yang hanya bersisa 2 indikator, variabel job environment yang juga bersisa 2 indikator dan variabel internal motivation juga tersisa 2 indikator. Dari gambar 4.4 dapat disimpulkan bahwa pengaruh job satisfaction terhadap internal motivation sebesar -0.39 , job environment terhadap internal motivation sebesar 0.31, job environment terhadap keinginan untuk keluar 0.31, pengaruh internal motivation terhadap keinginan untuk keluar sebesar -0.05 dan pengaruh job environment terhadap keinginan untuk keluar sebesar -0.35 .

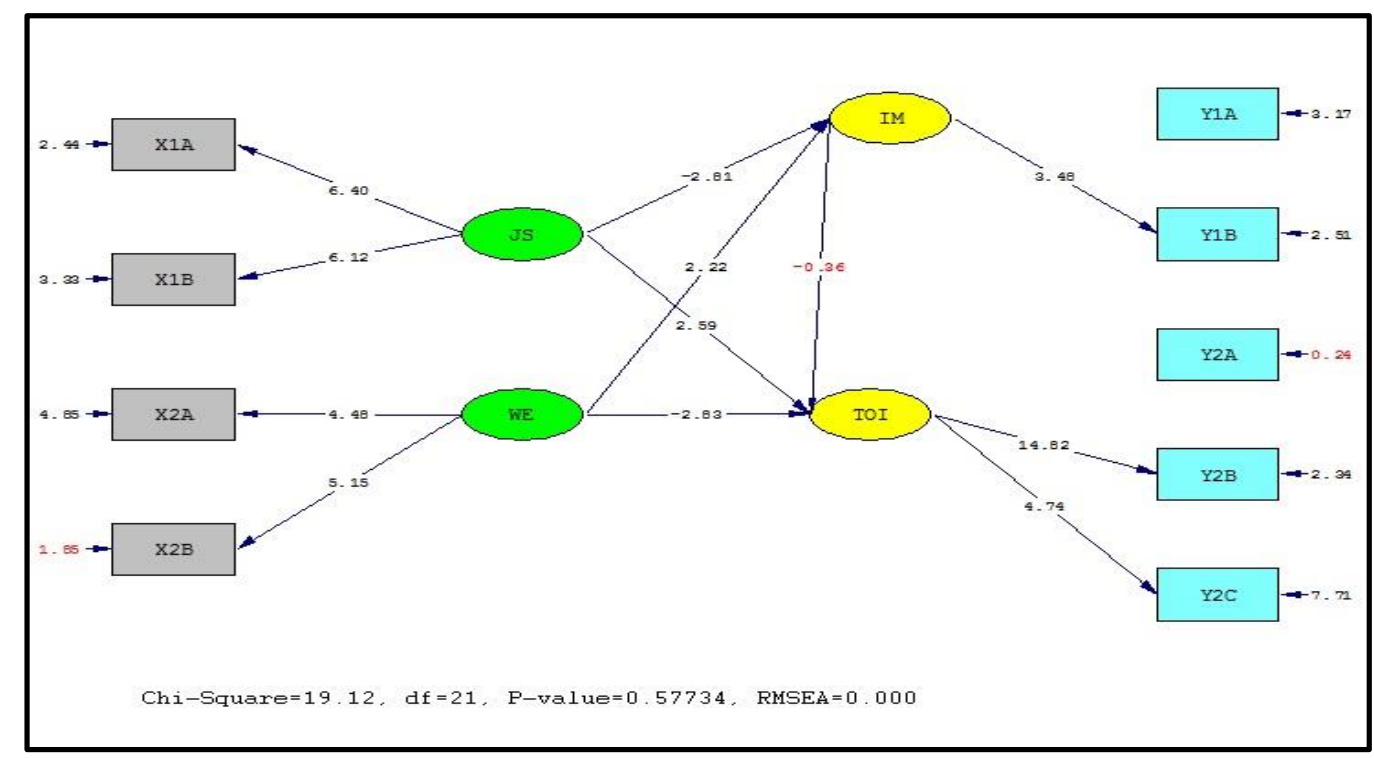

\section{Gambar 3 t-value revisi}

Setelah dilakukan droping x1c dan x2c karena loading factor yang teramat kecil, maka di lakukan uji t-value ulang untuk melihat apakah ada perubahan pada tingkat signifikan indikator per variabel. Dalam gambar 4.5 didapatkan tidak ada satu indikator variabel dari model tersebut yang tidak signifikan. Hanya hubungan antara internal motivation terhadap keinginan untuk keluar yang tidak signifikan (tidak berpengaruh) sedangkan hubungan antar variabel lain tetap signifikan.

\section{Uji pengaruh Langsung dan Tidak Langsung}

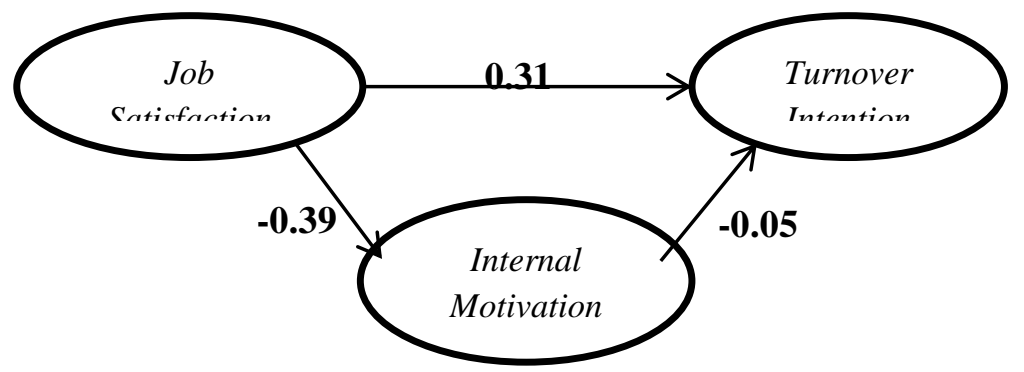

Gambar 4 Uji pengaruh langsung dan tidak langsung 1 
Dari gambar 4.4 bisa disimpulkan besar pengaruh langsung job satisfaction terhadap keinginan untuk keluar adalah sebesar 0.31. Pengaruh tidak langsung didapatkan dari hasil pengaruh variabel bebas ke variabel mediator dikalikan dengan pengaruh variabel mediator terhadap variabel dependent, yaitu $-0.39 \times-0.05=0.0195$. Karena hasil pengaruh tidak langsung lebih kecil dari pengaruh langsung, maka disimpulkan tidak terjadi pengaruh mediasi dari variabel mediator yaitu internal motivation.

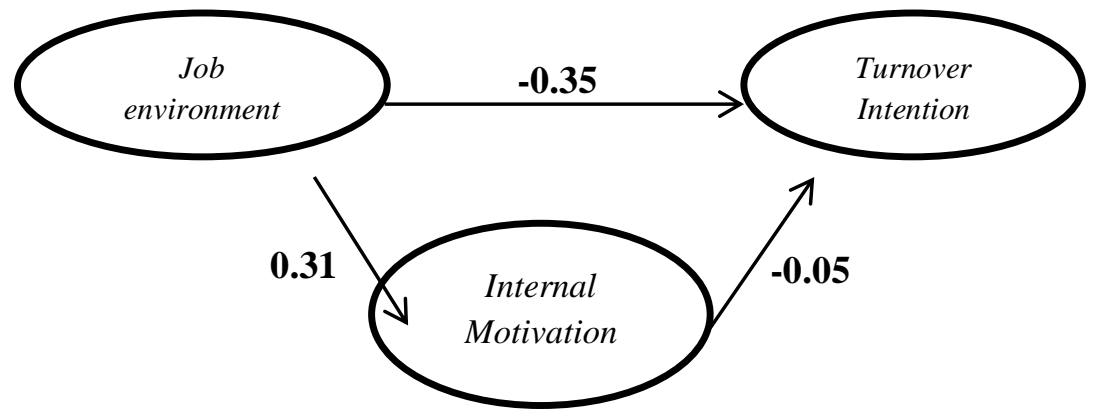

\section{Gambar 5 Uji pengaruh langsung dan tidak langsung 2}

Dari gambar 4.5 dapat disimpulkan besar pengaruh langsung job environment terhadap keinginan untuk keluar sebesar -0.35 . Sedangkan pengaruh tidak langsung didapatkan dari hasil pengaruh variabel bebas ke variabel mediator dikalikan dengan pengaruh variabel mediator terhadap variabel dependent, yaitu $0.31 \times-0.05=-0.0155$. Karena hasil pengaruh tidak langsung lebih kecil dari pengaruh langsung maka disimpulkan bahwa tidak terjadi pengaruh mediasi dari variabel mediator yaitu internal motivation.

\section{Uji Hipotesis}

Hasil uji hipotesis dapat disajikan sebagai berikut ini

Tabel 6 Ringkasan Hasil Uji Hipotesis

\begin{tabular}{|l|l|c|c|c|}
\hline No & \multicolumn{1}{|c|}{ Hipotesis } & t-hitung & Simpulan \\
\hline 1 & $\begin{array}{l}\text { Job satisfaction berpengaruh terhadap internal } \\
\text { motivation }\end{array}$ & $-2,61$ & Diterima \\
\hline 2 & $\begin{array}{l}\text { Job environment berpengaruh terhadap internal } \\
\text { motivation }\end{array}$ & 2,22 & Diterima \\
\hline 3 & $\begin{array}{l}\text { Job satisfaction berpengaruh terhadap turn over } \\
\text { intention }\end{array}$ & 2,59 & Diterima \\
\hline 4 & $\begin{array}{l}\text { Internal motivation berpengaruh terhadap turnover } \\
\text { intention }\end{array}$ & $-0,26$ & Ditolak \\
\hline 5 & $\begin{array}{l}\text { Job environment berpengaruh terhadap turnover } \\
\text { intention }\end{array}$ & $-2,82$ & Diterima \\
\hline
\end{tabular}




\section{Pengaruh Job Satisfaction terhadap Internal Motivation}

Penelitian ini mendapatkan hasil bahwa job satisfaction berpengaruh negatif dan signifikan terhadap internal motivation. Keadaan ini mengartikan bahwa jika perawat merasa puas dengan pekerjaan berarti internal motivation nya menurun. Hasil statistik diskriptif menunjukkan bahwa nilai rata-rata indek job satisfaction adalah 7,8 memiliki kategori tinggi. sedangkan nilai rata-rata indeks internal motivation adalah 7 dan masuk kategori tinggi.Berdasarkan hasil wawancara dengan responden diperoleh informasi, bahwa sesungguhnya mereka sudah merasa puas dengan pekerjaan selama ini, namun mereka merasa belum diberikan kesempatan untuk belajar tentang hal-hal yang baru yang ada di job environment mereka. Hal inilah yang menjadi salah satu pemicu turunnya internal motivation responden. Temuan ini berbanding terbalik dengan penelitian Baez (2017) yang menyatakan job satisfaction berdampak positif terhadap internal motivation. Peneliti Bakhtawar (2016) juga menyatakan job satisfaction mempunyai hubungan dengan internal motivation tetapi tidak terlalu signifikan. Namun hasil penelitian ini senada dengan hasil penelitian Agung et,al (2012) yang menyatakan job satisfaction tidak berpengaruh secara signifikan terhadap internal motivation.

\section{Pengaruh Job environment terhadap Internal Motivation}

Penelitian ini mendapatkan hasil bahwa job environment berpengaruh signifikan terhadap internal motivation. Hal ini menggambarkan jika job environment tercipta nyaman maka akan menaikan internal motivation dari perawat untuk tetap tinggal di dalam organisasi. Hasil perhitungan angka indeks variable job environment adalah 7,8 masuk kategori tinggi, sedangkan hasil perhitungan angka indeks internal motivation adalah 7 dan memiliki kategori tinggi. Hasil penelitian ini sama dengan hasil penelitian Mujib (2013), Lezita (2010) dan Astarina et,al (2017) yang menyatakan job environment berpengaruh signifikan terhadap internal motivation.

\section{Pengaruh Job Satisfaction terhadap Turnover Intention}

Penelitian ini mendapatkan hasil bahwa job satisfaction berpengaruh signifikan terhadap keinginan untuk keluar. Hasil perhitungan angka indeks dari variable job satisfaction sebesar 7,4 termasuk dalam kategori tinggi. Sedangkan hasil perhitungan angka indeks untuk variable turnover intention adalah 7,03 masuk kategori tinggi. Hal ini dapat diartikan, meskipun seoarang perawat merasa memiliki kepuasan dengan pekerjaan yang dilakukan sekarang, namun jika yang bersangkutan merasa masa depannya terhambat, tidak ada jenjang karir yang jelas, maka hal tersebut akan memicu untuk mencari peluang berkarir di tempat yang lain. Hasil penelitian ini berbanding terbalik dengan hasil penelitian Ahmed et,al (2015), Andini (2006), Anoki (2016), Saeer (2014) dan Astri (2014) yang menyatakan job satisfaction berpengaruh negatif tidak signifikan terhadap keinginan untuk keluar. Peneliti Lee (2011) juga menyatakan job satisfaction tidak berpengaruh secara langsung terhadap keinginan untuk keluar. Namun hasil penelitian ini senada dengan hasil penelitian Ashrafq (2016), Rafiqul (2016) dan Noorliza (2016) yang menyatakan job satisfaction berpengaruh terhadap keinginan untuk keluar. 


\section{Pengaruh Internal Motivation terhadap Turnover Intention}

Penelitian ini mendapatkan hasil bahwa internal motivation tidak berpengaruh terhadap keinginan untuk keluar. Hasil perhitungan angka indeks variable internal motivation adalah 7 masuk kategori tinggi. Variabel ini dibentuk oleh tiga indikator yaitu memanfaatkan potensi, belajar hal yang baru dan kreatif. Sedangkan variable turnover intention yang dibentuk oleh tiga indikator yaitu pencarian pekerjaa, pemikiran untuk keluar dan memimpikan berkarir di perusahaan lain memiliki angka indeks 7,03 dan berkategori tinggi. Hal ini menunjukkan jika perusahaan bisa memanfaatkan potensi yang dimiliki oleh karyawannya dan mau memberikan kesempatan untuk mempelajari hal-hal yang baru, yang berkaitan dengan pekerjaannya melalui pelatihan-pelatihan internal atau eksternal, maka hal ini akan dapat meningkatkan internal motivation karyawan, sekaligus dapat meredam turnover intention. Hal studi ini berbeda dengan hasil penelitian Dewi et,al (2016), Dwi et,al (2014) dan Widiawati et, (2017) yang menyatakan internal motivation berpengaruh terhadap keinginan untuk keluar.

\section{Pengaruh Job environment terhadap Turnover Intention}

Penelitian ini mendapatkan hasil bahwa job environment berpengaruh negatif signifikan terhadap keinginan untuk keluar. Job environment dibentuk oleh tiga indikator yaitu hubungan antar karyawan, suasana kerja dan fasilitas-fasilitas yang dinikmati karyawan. Job environment memiliki angka indeks 7,8 masuk kategori tinggi. Jika indikator-indikator tersebut bisa dikelola dengan baik oleh perusahaan, maka akan bisa menurunkan turnover intention yang ada. Hasil wawancara menunjukkan bahwa hubungan antar sesama karyawan dan atasan, suasana kerja yang menyenangkan dan penuh kekeluargaan akan membuat mereka betah untuk tetap tinggal di dalam organisasi. Hasil penelitian ini berbeda dengan hasil penelitian Imran (2012) yang menyatakan job environment berpengaruh signifikan terhadap keinginan untuk keluar. Hasil penelitian ini mendukung hasil penelitian Suryo (2016) dan Mamiharisoa (2015) yang menyatakan job environment berpengaruh terbalik dengan keinginan untuk keluar.

\section{PENUTUP}

Berdasarkan hasil uji statistic dan pembahasan yang telah dilakukan dalam studi ini, maka variable internal motivation ternyata tidak dapat memediasi pengaruh hubungan antara job satisfaction dan job environment terhadap turnover intention. Pengaruh kedua variable tersebut terhadap variable turnover intention merupakan pengaruh langsung. Guna menurunkan turnover intention di Semarang Medical Center Telogorejo, maka pihak manajemen perlu memberikan kesempatan promosi yang seluas-luasnya bagi semua karyawan yang benar benar memiliki prestasi yang baik, oleh karena itu organisasi perlu memiliki careerpath yang jelas dan terstruktur. Agar mereka bisa menapaki karir sampai di puncak, maka diperlukan adanya pelatihan dan pengembangan yang berkesinambungan. Disamping itu, turnover intention bisa diturunkan dengan memperbaiki indikator job environment yaitu tentang fasilitas yang diberikan dan dinikmati oleh karyawan pada saat ini. Namun demikian, studi ini masih meninggalkan agenda penelitian yaitu perlunya menguji kembali peran dari internal motivation sebagai variable intervening. 


\section{DAFTAR PUSTAKA}

Ahmed, Saad Syed Aljunid, Ilker Dastan, Ruqiya Subhi, Mustafa Ali, Kurubaran, Sami Abdo.(2015), Job Satisfaction and Turnover Intention Among Iraqi Doctors - A Descriptive Cross-sectional Multicentre Study. Human Resources for Health pp.13:21.

Annisa, Auliya (2017) Pengaruh Ketidaksamaan Kerja, Job satisfaction, Dan Komitmen Organisasi Terhadap Turnover Intention Pada PT. Riau Crumb Rubber Factory (RICRY) Pekanbaru. Faculty of Economic Riau University

Andrinirina, Mamiharisoa (2015) Pengaruh Job environment dan Job Insecurity terhadap Kinerja dan Turnover Intention Karyawan Pada Royal Hotel n'Lounge Jember. Universitas Jember : 2015.

Ashrafq, M; Nawaz Ahmad, Sheema Haider (2016) Antecedents of Turnover Intentions : A Study of Karachi Business Schools. Journal of Business Studies, Vol.12, No.1, (Spring) 139-156.

Baez, Andrea Maria Devesa. (2017), Motivation, Satisfaction and Loyality in The Case of Film Festival : Differences Between Local And Non-local Participans. J Colt Econ 41:173195.

Chang, Chun; Sheng-Hsiung, Chen-Yi. A Study on Factors Affecting Turnover Intention of Hotel Employees. Asian Economic and Financial Review 2(7):866-875.

Chen, Man Ling; Zhi-Yuan SU, Chian-Lun Lo, Chiung-Hsian Chiu, Ya-Han Hu, Tien-Yu Shieh (2013) An Empirical Study On The Factors Influencing The Turnover Intention Of Dentist In Hospital Taiwan.Journal of Dental Sciences, Taiwan

Cinar, Orhan, Fatih Karcioglu, Imran Aslan (2014). The Relationship Among Organizational Cynicism, Job Insecurity and Turnover Intention: A Survey Study In Erzurum. Procedia Social and Behavioral Sciences, Taiwan

Cho, Seonghee ; Misty M. Johansen, Priyanko Guchait,(2009), Employees Intent To Leave : A Comparison Of Determinants Of Intent To Leave Versus Intent To Stay. International Journal of Hospitality Management, Elsevier

Ghofur, Abdul; Bambang Syairudin; M.Yusak Anshori, (2017), Pengaruh Motivasi Instrinsik dan Ekstrinsik Terhadap Kinerja Karyawan Divisi Network Operations PT XYZ Surabaya. Surabaya : 2017.

Herdian, Anoki; Ahyar Yuniawan. (2016), Pengaruh Perilaku Pemimpin, Keadilan Kompensasi dan Stres Kerja Terhadap Job satisfaction Serta Implikasinya pada Intention to Quit Karyawan. Universitas Diponegoro, Semarang

Hanaysha, Jalal, (2016), Testing The Effects Of Emplotee Engagement, Job environment and Organizational Learning on Organizational Commitment. University of Automotive Malaysia

Islam, Rafiqul; Tanzia Rahman. (2016) Relationship between Job Satisfaction, Orfanizational Commitment and Turnover Intention Among Bank Employees : A Study on Selected Banks of Bangladesh. Scholar Journal of Business and Social Science, Vol.2, No.1 7-18.

Kamasak, Rifat, (2011) The Influence of Perceived External Prestige on Job Satisfaction and Turnover Intentions. Journal of Business and Economics, Vol.2, No.3, pp. 209-221.

Khairani, Diana, (2013) Pengaruh Job environment Terhadap Kinerja Pegawai BAPPEDA. Universitas Malikusaleh, Aceh 
Kumar, Kuldeep, (2008), Perceived Organizational Justice, Job Satisfaction and Turnover Intentions : A Co-relational Study. Trikuta Degree College, Jammu

Lezita (2010), Pengaruh Job environment Terhadap Motivasi Kerja Karyawan Pada PT Sinar Sosro Kantor Penjualan Bogor. Institut Pertanian Bogor

Oswald, Asigele, (2012) The Effect of Working Environment on Workers Performance : The Case of Reproductive and Child Health Care Providers In Terime District. University of Health and Allied Sciences, Muhimbli

Prihantoro, Agung. (2012) Peningkatan Kinerja Sumber Daya Manusia Melalui Motivasi, Disiplin, Job environment, Dan Komitmen. Value Added, vol.8, No.2, Maret

Qureshi,M. Imran (2012). Job Stress, Workload, Environment and Employees Turnover Intentions: Destiny or Choice. COMSATS Institute of Information Technology, Pakistan

Ridwan Suryo. Pengaruh Job satisfaction, Job environment dan Kompensasi Terhadap Turnover Intention Karyawan Dengan Lama Kerja Sebai Variabel Permoderasi. UNY, Yogyakarta : 2016.

Saeed, Igra; Momina Waseem, Sidra Sikander (2014) The Relationship of Turnover Intention With Job Satisfacton, Job Performance, Leader Member Exchange, Emotional Intelligence and Organizational Commitment. International Journal of Learning \& Development, Vol.4, No.2

Ummi, Saraih ,Ain Zuraini, Sakdan, Ahmad Razli. (2017), Factors Affecting Turnover Intention Among Academician in The Malaysian Higher Education Institution. Review of Inegrative Business \& Economics Research Vol.6, No.1,

Waspodo, Agung AWS; Lussy Minadaniati (2012), Pengaruh Job satisfaction Dan Iklim Organisasi Terhadap Organizational Citizenship Behaviour (OCB) Karyawan Pada PT.Trubus Swadaya Depok. Depok

Widiawati, Firda; Dheasey Amboningtyas, Amanda Mastisia, Moh.Mukeri (2017). Pengaruh Beban Kerja, Stres Kerja dan Motivasi Kerja Terhadap Turnover Intention Karyawan PT GEOGIFEN VISI MANDIRI Semarang. Universitas Pandanaran, Semarang

Wulandari,Astri; Fanny Martdianty. The Effect of Employer Brand on Voluntary Turnover Intention With Mediating Effect of Organizational Commitment and Job Satisfaction. Universitas Indonesia Research Paper Series No. 13-66.

Zainol, Noorliza; Abdul Rahman, Nakia Nordin, Farina Nozakiah, Putri Dahlia (2016). Employees Dissatisfaction and Turnover Crises : A Study of Hotel Industry, Malaysia. University Teknologi MARA, Malaysia

Zhang, Yanjuan, (2016) A Review of Employee Turnover Influence Factor and Countermeasure. Journal of Human Resource and Sustainability Studies, 4, 85-91. 